\title{
Comunicação
}

[Communication]

\section{Purificação de IgG de codorna a partir de soro e gema de ovos}

\author{
[Purification of Japanese quail IgG from serum and egg yolk] \\ D.D. Oliveira ${ }^{1}$, J.S. Resende ${ }^{1 *}$, A.V.F. Flatschart ${ }^{1}$, J.T. Abreu ${ }^{2}$, R.B. Flatschart ${ }^{1}$, N.R.S. Martins ${ }^{1}$ \\ ${ }^{1}$ Escola de Veterinária - UFMG \\ Caixa Postal, 567 \\ 30123-970 - Belo Horizonte, MG \\ ${ }^{2}$ Curso de Medicina Veterinária - PUC - Betim, MG
}

\begin{abstract}
A IgG é a imunoglobulina encontrada em maior concentração no soro das aves, pode passar para o ovo, conferindo imunidade passiva para o pintinho recém-eclodido (Rosenberg, 1996; Tini et al., 2002). A gema de ovo pode ser usada em testes sorológicos, porém, devido à grande quantidade de lipídeos presentes, os anticorpos precisam ser purificados (Tini et al., 2002). Os testes sorológicos convencionais utilizados para codornas (Coturnix coturnix japonica) têm sido baseados naqueles padronizados para galinhas (Gallus gallus formadomestica). Por isso, os objetivos deste trabalho foram a avaliação e a purificação de $\mathrm{IgG}$, em amostras de soro e gema de ovos de codorna, para futura utilização em testes sorológicos.
\end{abstract}

A purificação de IgG do soro de codornas foi realizada segundo Bhanushali et al. (1994), com modificações. Foram usados $10 \mathrm{~mL}$ de soro de codorna diluído a 1:5 em tampão acetato. A este material foi adicionado ácido caprílico na proporção de $25 \mu \mathrm{L} / \mathrm{mL}$ de soro, mantido overnight a 4C. $\mathrm{O}$ sobrenadante foi removido após centrifugação a 10.000 x g $\left(30 \mathrm{~min} / 4^{\circ} \mathrm{C}\right)$, filtrado em membrana $(0,2 \mu \mathrm{m}$, Millipore) e diluído com PBS (pH 7,2) na proporção 1:10. Uma segunda precipitação foi feita adicionandose solução saturada de sulfato de amônio tamponada ( $\mathrm{pH} 7,0)$, até atingir $36 \%$ de saturação final. Após centrifugação a 10.000 x g $\left(30 \mathrm{~min} / 4^{\circ} \mathrm{C}\right)$, o pellet foi ressuspendido em $1 \mathrm{~mL}$ de PBS (pH 7,2) e dialisado. As amostras foram armazenadas a $4^{\circ} \mathrm{C}$ sem conservantes como sugerido por Otani et al. (1993).

Recebido em 2 de fevereiro de 2009

Aceito em 29 de janeiro de 2010

*Autor para correspondência (corresponding author)

E-mail: jsresendvet@yahoo.com.br
A purificação de $\operatorname{IgG}$ da gema de ovos de codorna foi realizado segundo Akita e Nakai (1992), Abbassi et al. (1999) e Bizhanov e Vyshniauskis (2000).

Para obtenção de $\mathrm{IgG}$, a mistura contendo clorofórmio, pool de gemas e água $18,2 \mathrm{~m} \Omega$ acidificada com $\mathrm{HCl} 0,1 \mathrm{~N}$ ( $\mathrm{pH}$ final 5,0 a 5,2), foi centrifugada a $3000 \times \mathrm{g} 30 \mathrm{~min} /$ temperatura ambiente (TA) para separação das fases. A fase aquosa superior, que continha a $\mathrm{IgG}$, foi coletada, e para cada $10 \mathrm{~mL}$ desta fase aquosa foram adicionados $5 \mathrm{~mL}$ de uma solução $36 \%$ (p/v) PEG-6000 (Sigma Aldrich - St. Louis, EUA), a mistura foi mantida em repouso por $30 \mathrm{~min}\left(4^{\circ} \mathrm{C}\right)$. O pelete, obtido por centrifugação a 3000 x g (10min/TA), foi ressuspendido em PBS (pH 7,2), em volume equivalente a $1 \%$ do volume original de gema utilizada. A precipitação da $\mathrm{IgG}$ foi realizada com etanol ($\left.20^{\circ} \mathrm{C}\right)$ numa mistura final de $50 \%(\mathrm{v} / \mathrm{v})$ e centrifugação a 10.000 x g $\left(30 \mathrm{~min} / 4^{\circ} \mathrm{C}\right)$. O precipitado foi ressuspendido com PBS em $25 \%$ do volume do pool de gemas inicial, dividido em placas de Petri estéreis e colocado em estufa de $37^{\circ} \mathrm{C}$ por $2 \mathrm{~h}$ para a evaporação do álcool. Os sólidos foram ressuspendidos no mesmo volume inicial da gema com água $18,2 \mathrm{~m} \Omega$ estéril, e a dosagem de proteína foi feita pelo método de Lowry, utilizando-se o kit protein assay ${ }^{1}$.

Para confirmar o grau de pureza das amostras de IgG purificadas do soro e da gema de ovos de codornas, foi feita eletroforese em gel de poliacrilamida (SDS-PAGE) a $10 \%$, corado com azul de Comassie (Makkay et al., 1999). Para confirmar a identidade das proteínas purificadas, se compatíveis coma massa molecular de IgG 
(Makkay et al., 1999), foi realizado o western blot.

Após bloqueio da membrana de nitrocelulose com leite em pó desnatado 3\%, foi adicionado IgG de coelho anti-IgG de galinha (Sigma Aldrich), na diluição 1:5000, com posterior lavagem com PBS tween 20 0,5\%. A revelação foi feita com o seguinte substrato: $10 \mathrm{~mL}$ de tampão AP (Tris $\mathrm{HCl} \mathrm{pH} 9,5, \mathrm{NaCl}, \mathrm{MgCl}_{2}$ ) $64 \mu \mathrm{L}$ de nitro blue tetrazolium (Sigma Aldrich), e $34 \mu \mathrm{L}$ de BCIP (5-bromo, 4-chloro, 3 indolylphosphate (Promega Co.- Madison, EUA), mantido em agitação à TA até o aparecimento das bandas. Para interromper reação, o substrato foi descartado e a membrana lavada três vezes com água $18,2 \mathrm{~m} \Omega$ estéril por $15 \mathrm{~min}$.

Determinou-se a concentração de proteína das amostras de IgG purificada do soro e da gema de ovos de codorna. As amostras de IgG dos soros tinham, em média, 4939,4 $\mu \mathrm{g}$ de proteína total $/ \mathrm{mL}$ e as das gemas $7467,5 \mu \mathrm{g}$ de proteína total $/ \mathrm{mL}$. Na Tab. 1 mostram-se as concentrações de proteína ( $\operatorname{IgG})$ obtidas de cada amostra.

Tabela 1. Concentração de proteína das amostras de IgG purificadas do soro e das gemas dos ovos de codornas

\begin{tabular}{lcc}
\hline \multirow{2}{*}{ Amostra } & \multicolumn{2}{c}{ Proteína $(\mu \mathrm{g} / \mathrm{mL})$} \\
\cline { 2 - 3 } & IgG purificada do soro & IgG purificada da gema \\
\hline Amostra (1) & $6285,7 \mathrm{a}$ & $6454,5 \mathrm{a}$ \\
Amostra (2) & $5428,6 \mathrm{~b}$ & $7532,4 \mathrm{~b}$ \\
Amostra (3) & $3103,9 \mathrm{c}$ & $8415,6 \mathrm{c}$ \\
Média & 4939,4 & 7467,5 \\
\hline
\end{tabular}

$(1,2,3)$ : primeira, segunda e terceira centrifugações.

Pela análise de cada amostra de IgG purificada, observa-se que a concentração de proteínas decresce à medida que é feita uma nova centrifugação. As concentrações de proteína obtidas da purificação de $\operatorname{IgG}$ do soro e das gemas dos ovos de codorna apresentaram coerência com os resultados encontrados em estudos anteriores (Otani et al., 1993; De Meulenaer e Huyghebaert, 2001; Tini et al., 2002) para purificação de IgG de galinha.
Os resultados da eletroforese (SDS-PAGE) e western blot confirmaram a purificação das amostras (Fig. 1). Na eletroforese, verificou-se a separação das cadeias leve e pesada das imunoglobulinas do soro, com aproximadamente 25 e $65 \mathrm{kDa}$, respectivamente, que coincidiram com o padrão de tamanho molecular utilizado (Fig. 1A). No SDS-PAGE, IgG purificada de gema, (Fig. 1A, canaletas 5 e 7), foi possível observar a presença das bandas, com tamanho molecular em torno de $45,5 \mathrm{kDa}$, diferentes das cadeias leve e pesada de IgG da amostra padrão.

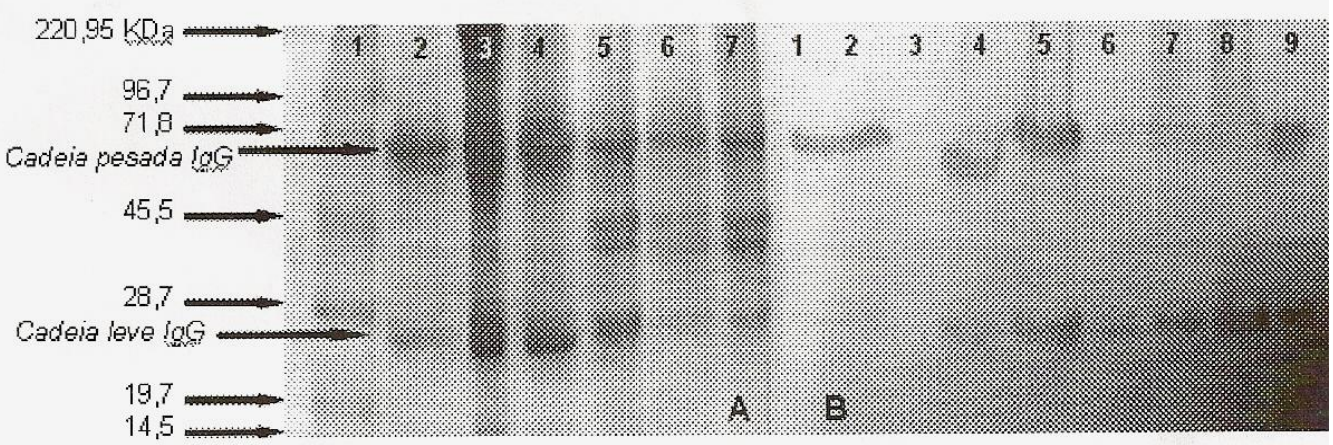

Figura 1. A) Eletroforese em SDS-PAGE, corado com azul de Coomassie das amostras de IgG purificadas do soro e das gemas dos ovos de codorna. Canaletas - 1: padrão de tamanho molecular 14,5 a 220,95KDa; 2, 3, 4: IgG do soro de codornas; 5, 6, 7: IgG da gema de ovos de codornas. B) Membrana de nitrocelulose do western blot das amostras de IgG purificadas do soro e gema de ovos de codorna e IgG de galinha, revelada com IgG de coelho anti-IgG de galinha e corada com NBT e BCIP. Canaletas - 1, 2, 4, 5: IgG da gema de ovos de codornas; 6: de IgG galinha; 7, 8, 9: IgG do soro de codorna; 3: tampão de amostra. 
A membrana de western blot, revelada, confirmou a identidade das bandas das cadeias leve e pesada do gel de SDS-PAGE. Os dados encontrados de eletroforese assemelham-se aos resultados de De Meulenaer e Huyghebaert (2001), mostrando a eficiência dos processos de purificação para IgG do soro e da gema dos ovos de codorna. Provavelmente, devido à grande concentração de IgG na gema dos ovos de codorna, o processo de separação das cadeias leves e pesada da IgG não tenha sido totalmente eficiente, devido à presença de outra banda, com tamanho molecular em torno de 45,5kDa. Essa banda, provavelmente, refere-se à ovalbumina, proteína presente em grande quantidade na gema do ovo (Otani et al., 1993). Quando revelada a membrana de western blot, foi possível verificar a identidade das bandas das cadeias leve e pesada das IgG do gel de SDS-PAGE. Para confirmar os dados utilizou-se, também, da amostra de IgG de galinha comercial purificada. $O$ padrão de bandas encontrado no SDS-PAGE e western blot foram semelhantes.

Com base nos dados de dosagem de proteína, foi comprovada a eficiência dos métodos utilizados para purificação de $\operatorname{IgG}$ de codornas a partir do soro e da gema de ovos.

Palavras-chave: codorna, imunoglobulina, gema de ovo, purificação, soro de codorna

\begin{abstract}
The purification of Japanese quail IgG from serum was performed using caprilic acid and ammonium sulfate, and from egg yolk using PEG-6000 and ethanol. After confirming the purification and the concentration of $\operatorname{Ig} G$, the yolk samples had twice the amount of protein compared to serum samples. The IgG extracts were analyzed by SDS-PAGE and western blot showing similar results as the ones of chicken IgG used as the standard. So, these methodologies can be used for purifying quail serum or egg yolk IgG, which would enable the development of diagnostic assays.
\end{abstract}

Keywords: quail, immunoglobulin, egg yolk, purification, quail serum

\section{REFERÊNCIAS BIBLIOGRÁFICAS}

ABBASSI, P.H.; TOQUIN, D.; GUITTET, M. et al. Comparaison de trois méthodes d'extraction des immunoglobulines vitellines: application à l'extraction d'anticorps neutralisant dans le virus de la bursite infectieuse. Rec. Med. Vet., v.3, p.107-117, 1999.

AKITA, E.M.; NAKAI, N. Immunoglobulins from egg yolk: isolation and purification. J. Food Sci., v.57, p.629-634, 1992.

BHANUSHALI, J.K.; GILBERT, J.M.; McDOUGALD, L.R. Simple method to purify chicken immunoglobulin G. Poult. Sci., v.73, p.7-9, 1994.

BIZHANOV， G.; VYSHNIAUSKIS， G.A. Comparison of three methods for extracting IgY from the egg yolk of hens immunized with Sendai virus. Vet. Res. Commun., v.24, p.103$113,2000$.

DE MEULENAER, B.; HUYGHEBAERT, A. Isolation and Purification of Chicken Egg Yolk Immunoglobulins: A Review. Food Agri. Immunol., v.13, p.275-288, 2001.
MAKKAY, A.; KRELL, P.J.; NAGY, E. Antibody detection-based differential ELISA for NDV-infected or vaccinated chickens versus NDV HN-subunit vaccinated chickens. Vet. Microbiol., v.66, p.209-222, 1999.

OTANI, H.; MATSUMOTO, K.; HIRAO, M. Antigenic reactivity of the egg yolk antibody in the Japanese quail towards the anti-chicken IgG antibody. Anim. Sci. Technol., v.64, p.28-31, 1993.

ROSENBERG, I.M. Protein and analysis and purification - Benchtop techniques. 2.ed. Boston: Birkhäuser Boston, 1996. 434p.

TINI, M.; JEWELL, U.R.; CAMENISCH, G. et al. Generation and application of chicken eggyolk antibodies. Comp. Biochem. Physiol. A, v.131, p.569-574, 2002. 